\title{
Experimental Study on the Bearing Capacity of Glass Deck under the Condition of Vehicle Traffic
}

\author{
Peng TANG*, Sai GONG, Peng LIANG, Gao CHENG
}

\begin{abstract}
In order to study the mechanical properties of the glass plate structure applied to the automobile bridge deck, the bearing capacity test of the glass bridge deck under the wheel load is carried out, and the failure mode, load displacement curve and safety function of the glass plate under the boundary, position and number of layers of the wheel load are analyzed. The results show that the ultimate bearing capacity of laminated glass under the condition of simply supported boundary on both sides is about four sides supported $71.8 \%$. The ultimate bearing capacity of single-layer glass under the boundary condition of simple support on both sides is about four sides $51.4 \%$ from the point of view of meeting the structural strength requirements. The loading test is carried out by applying different multiple wheel loads at the plate angle and the center of the plate. The test results can provide reference for the application of the glass bridge deck in engineering.
\end{abstract}

Keywords: bearing capacity experiment; boundary condition; glass plate; wheel load; wheel pressure position

\section{INTRODUCTION}

The diversified demands of architectural glass promote the rapid development of glass production, molding and processing technology. At present, China's glass application has rapidly increased to become the third largest building material. The glass bridge deck is applied to the pedestrian landscape bridge with its advantages of light weight, high strength, good light transmittance, energy conservation and environmental protection, and has soon attracted scholars and bridge engineers at home and abroad and the attention of news media [1]. The strength of glass structure is different due to the load direction, type, boundary condition, type and thickness, and has certain discreteness [2]. In order to solve the stress analysis and calculation of pedestrian glass bridge deck in landscape area, Wang Xun [3] gives the analytical expression of stress and deformation of simply supported slab on four sides under uniform load; Wang Yuanqing [4-7] equates the inplane bending glass plate with simply supported or fixed supported plate beam on both sides, and points out that the bearing capacity of in-plane bending glass plate is proportional to the plate thickness, height span ratio, and inversely proportional to the span height ratio. Liu Qiang [8] analyzes the bending performance of laminated glass beam under short-term and long-term load. Yin Yongwei, Zhang Qilin [9] pair of point supported hollow and laminated glass under uniform load. The short-term and long-term load performance tests were carried out. Zhang Yangmei [10] and Zhang Zongheng [11] respectively carried out the experimental research on the failure modes of multilayer SGP laminated glass and PVB laminated glass under the impact of rigid body and low-speed impact. Tao Zhixiong et al. [12] carried out the load displacement curve close to the linear distribution under the static load on the simply supported laminated glass on four sides. At present, the research is widely collected in the theoretical calculation of the glass under the action of the uniform load. In the bridge engineering, the load is the wheel pressure of vehicle, which cannot be equal to the uniform load, and the existing analytical expression based on the plate and shell theory cannot be applied. In order to ensure the safety and reliability of the structure, the safety factor of the structure can only be increased. At present, the scientific research work only focuses on a certain bridge, and the bearing capacity test of bridge deck focuses on the confirmatory test, without the determination of the most unfavorable load position of the bridge deck and the related stress and deflection test, lack of in-depth research on the transmission mechanism, failure mode and ultimate bearing capacity, and has not formed a systematic design method. The application of the glass plate to the vehicle deck has not been seen yet, and the relevant experimental research and theoretical analysis research are few. In order to study the mechanical properties of the glass bridge deck applied to vehicle driving, this paper intends to select the number of glass layers, boundary conditions and the position of action as the starting point of the experimental study, and carry out the bearing capacity test of the glass bridge deck.

\section{TEST PLAN}

\subsection{Specimen Model}

It is determined that the design dimension of the single-layer toughened glass test piece is $120 \times 120 \mathrm{~cm}$ and the thickness is $12 \mathrm{~mm}$ (Tab. 1). The glass plate test piece shall conform to the national standard. According to the statistics of the vehicle weight of the mainstream models, the load is generally less than $30 \mathrm{kN}$, that is, the maximum wheel weight of a single wheel is $7.5 \mathrm{kN}$. The contact surface between the tire and the ground is elliptical. For the convenience of calculation, it is simplified as a rectangle, and the contact area is proportional to the total weight of the car and the width of the tire. The size of the contact surface of a single wheel of the car is $200 \times 100 \mathrm{~mm}$, and a $25 \mathrm{~mm}$ thick rubber pad is used to simulate the contact between the wheel and the glass.

Table 1 Specimen parameter

\begin{tabular}{|c|c|c|c|}
\hline No. & Type & Parameter & Quantity \\
\hline 1 & $\begin{array}{c}\text { Laminated } \\
\text { glass }\end{array}$ & $\begin{array}{c}12 \mathrm{~mm} \text { tempered glass }+1.56 \mathrm{~mm} \text { PVB } \\
+12 \mathrm{~mm} \text { tempered glass }+1.56 \mathrm{~mm} \\
\text { PVB }+12 \mathrm{~mm} \text { tempered glass }\end{array}$ & 16 \\
\hline 2 & $\begin{array}{c}\text { Single- } \\
\text { glass }\end{array}$ & $\begin{array}{c}12 \mathrm{~mm} \text { tempered glass(Same batch as } \\
\text { laminated glass) }\end{array}$ & 8 \\
\hline
\end{tabular}




\subsection{Test Equipment}

The instrument adopts $1000 \mathrm{kN}$ microcomputer controlled electro-hydraulic servo pressure testing machine in Shaanxi bridge structure laboratory. In the test, displacement sensor is used to measure the deformation of glass plate, and strain gauge is used to measure the change rule of strain on the outer surface of glass plate. Japan tds302 static data acquisition instrument is used to collect displacement and strain data, TDS data acquisition instrument is used to record the change curve of displacement and strain with load.

\subsection{Test Method}

In order to analyze the influence of boundary conditions on the failure mode and ultimate bearing capacity of glass plate, single-layer and three-layer PVB laminated glass plate is selected, and the boundary conditions of simple support on four sides and two sides are used to simulate the wheel load acting on the center, plate edge and plate angle of glass plate. The monotonous grading load is applied to the wheel load, and the load control grading is applied to 70 first \%. In order to obtain a smooth curve, the data collection should be properly encrypted. When the load is applied to $95 \%$ of the peak value, the load should be stopped. The maximum load during the loading process is taken as the ultimate bearing capacity of the test piece until the glass is damaged.

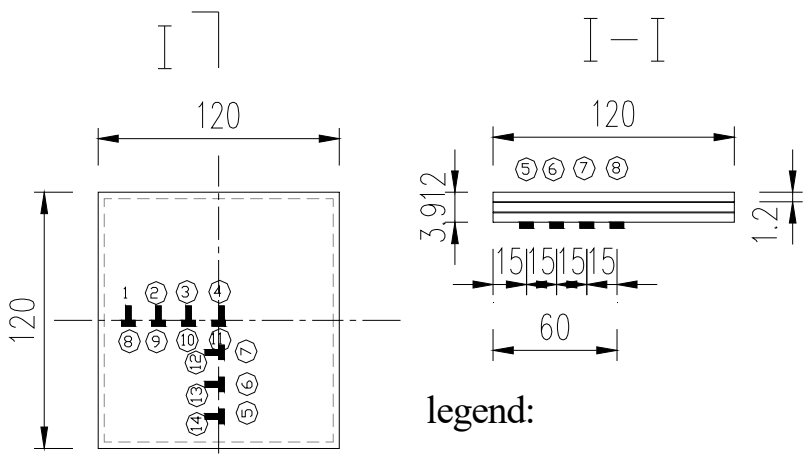

- strain measured point

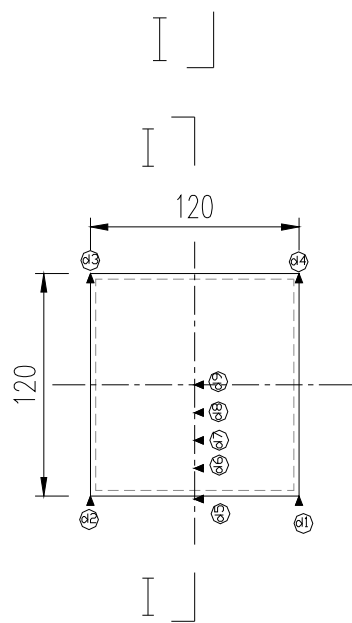

(a)

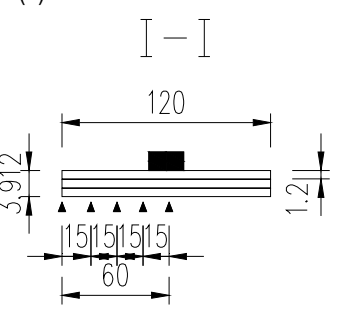

legend:

^ displacement measured point

(b)

Figure 1 Survey point arrangement: (a) Arrangement of strain measuring points of laminate glass; (b) Arrangement of displacement measuring points of laminate glass

\subsection{Layout of Measuring Points}

In the test, the displacement sensor is used to measure the deformation of the glass plate under the load, and the strain gauge is used to test the surface strain of the glass plate. The strain gauges are arranged at equal intervals along the length and width of the glass plate. The displacement and strain measuring points of the laminated glass are arranged at the same position as that of the single glass. The measuring points of the laminated glass are shown in Fig. 1, and the test temperature is normal temperature $\left(25^{\circ} \mathrm{C}\right)$.

\section{RESULTS AND ANALYSIS \\ 3.1 Layers of Glass Plate}

In order to analyze the influence of different layers of glass on the bearing capacity of the vehicle under the load, three-layer PVB laminated glass plate and single-layer glass specimen are selected for the test, and the load is concentrated in the center of the glass plate. The stress and failure modes of the laminated glass specimens are shown in Fig. 2. When the laminated glass specimens JG001, JG002 and JG003 reach the ultimate load, there is a "snap" sound, the most obvious one. The bottom glass is damaged in an instant. There are only a few pieces of broken small glass slag on the ground, and all less than $1 \mathrm{~cm}$. There are small cracks at the stressed part and large area network cracks at other parts.

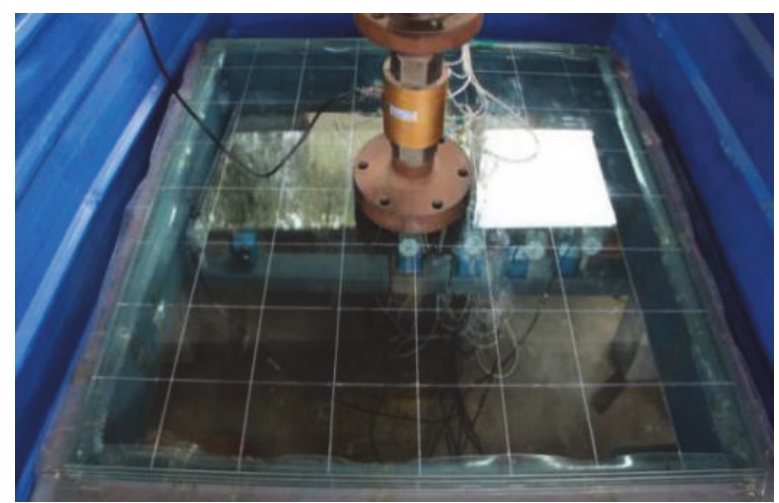

(a) Before destruction

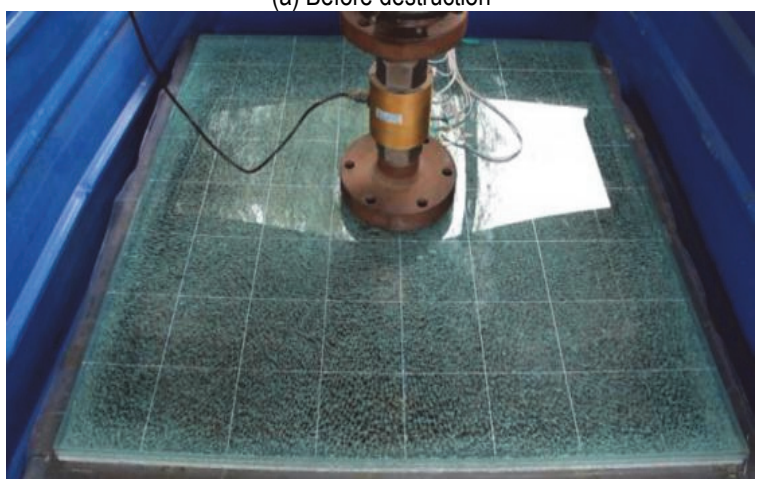

(b) After the destruction

Figure 2 Failure mode of laminated glass with four sides simply supported

Fig. 3 shows the load displacement curve in the center of laminated glass and single-layer glass plate. The load before the failure of glass plate is taken as the ultimate bearing capacity of the structure. It can be seen from the figure that the ultimate bearing capacity of laminated glass is respectively $58.5 \mathrm{kN}, 49.6 \mathrm{kN}, 72.1 \mathrm{kN}$, the average 
value of the three is $60.1 \mathrm{kN}$. The ultimate bearing capacity of single-layer glass DG001 is $21.6 \mathrm{kN}$.

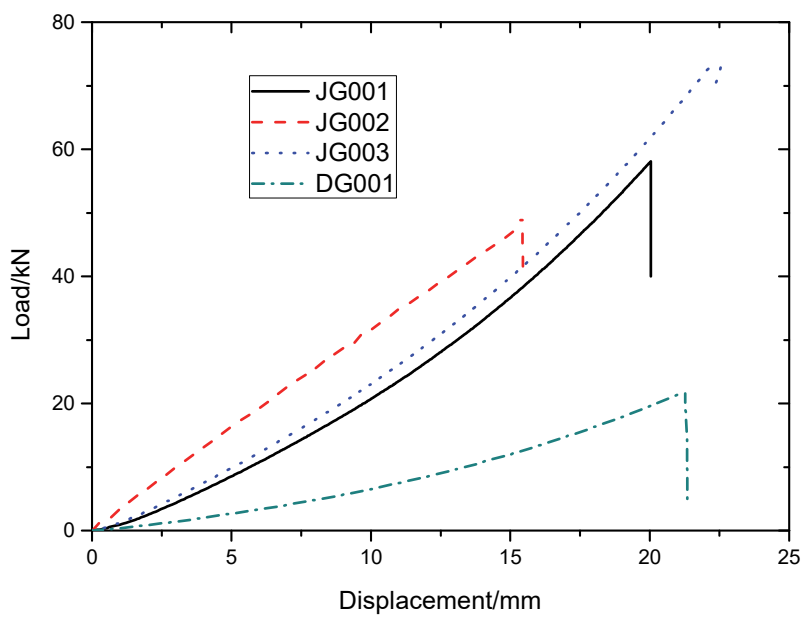

Figure 3 Load-displacement curve

\subsection{Boundary Conditions}

In order to study the influence of boundary support conditions on the bearing capacity of the vehicle under the load, laminated glass and single-layer glass are selected, and the glass is placed on the frame with simple supports on both sides and four sides, and the load is applied at the center of the glass plate, as shown in Fig. 4.

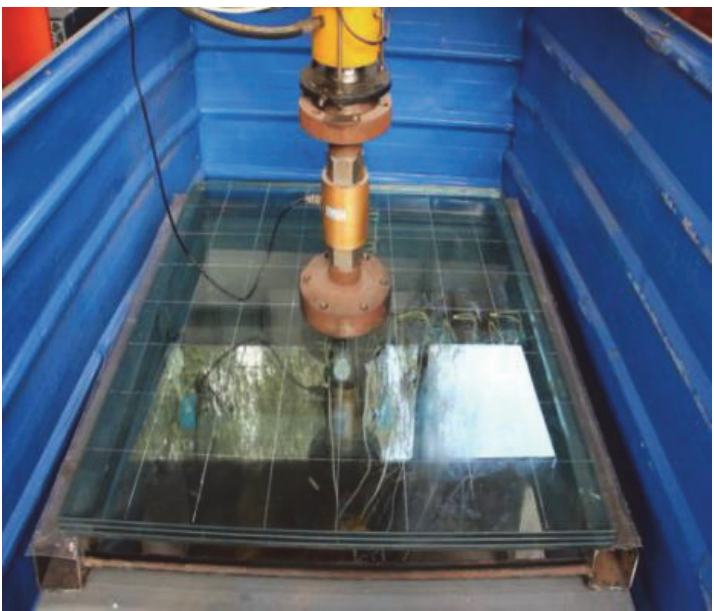

(a) Before destruction

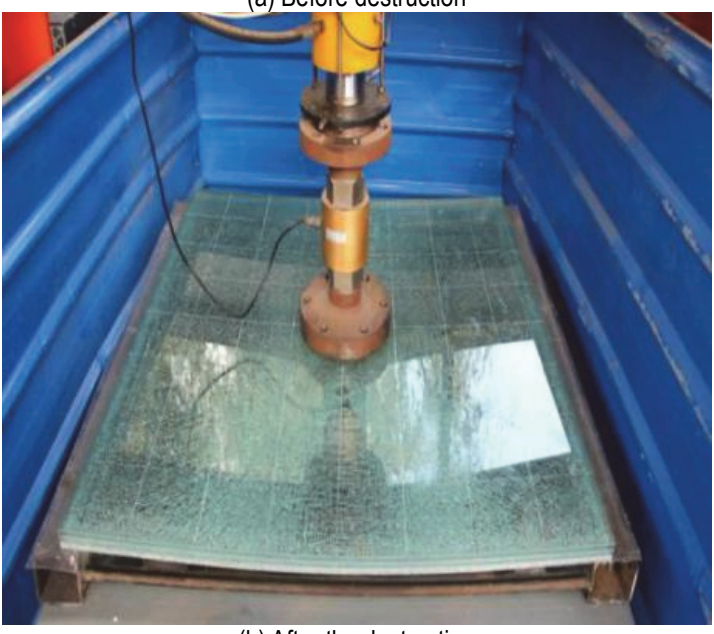

(b) After the destruction

Figure 4 Failure mode of laminated glass under the condition of support on both sides
Fig. 5 shows the load displacement curve of glass plate with simple support on four sides and two sides. The curve trend is the same under the two boundary conditions, showing a linear change. It can be seen from Fig. 5a that the ultimate bearing capacity of laminated glass JG001 is $58.5 \mathrm{kN}$ under the boundary condition of simple support on four sides, and the ultimate bearing capacity of laminated glass JG007 under the boundary condition of simple support on both sides is $42.0 \mathrm{kN}$, about $71.8 \%$ is supported by four sides. In Fig. 5b, the ultimate bearing capacity of single-layer glass DG001 is $21.6 \mathrm{kN}$ under the boundary condition of four simple supports, while the ultimate bearing capacity of single-layer glass DG004 under the boundary condition of two simple supports is $11.1 \mathrm{kN}$, about $51.4 \%$ of the four simple supports.

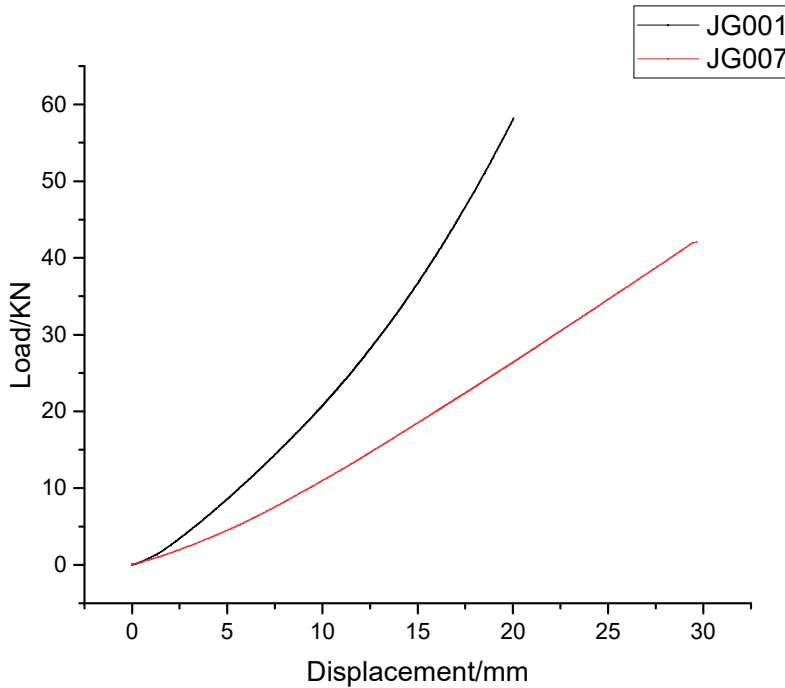

(a)

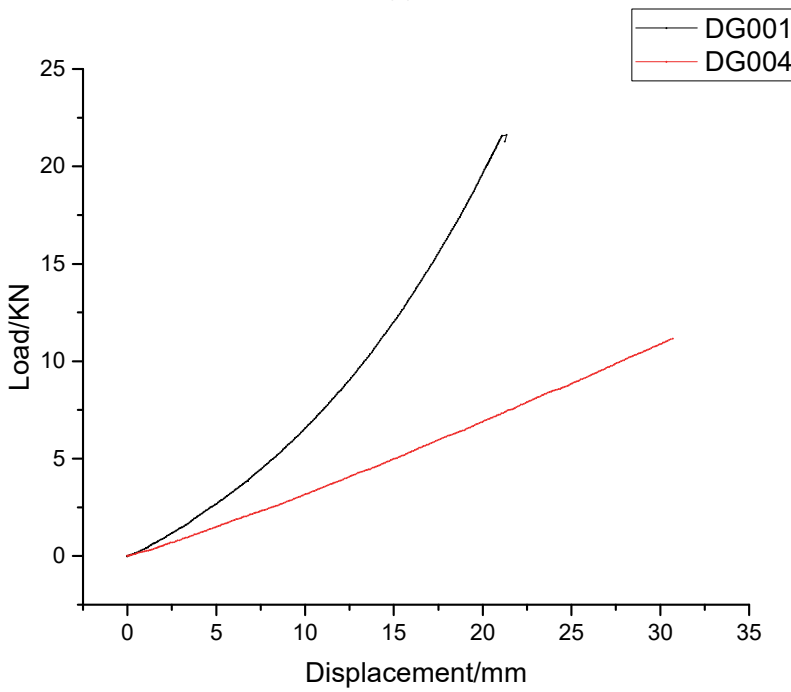

(b)

Figure 5 Load displacement curve of laminated glass under different boundary conditions: (a) Laminated glass and (b) Single layer glass

\subsection{Loading Position}

In order to analyze the bearing capacity of glass bridge deck under different wheel pressure positions, laminated glass and single-layer glass are selected to simulate the bearing capacity of two kinds of glass when the wheel load acts on the central position, edge position and corner position of the glass. It can be seen from Fig. 6a that the 
ultimate bearing capacity of laminated glass is about 60.0 $\mathrm{kN}$ when it acts on the central position, about $59.0 \mathrm{kN}$ when it acts on the edge of the plate, and about $59.0 \mathrm{kN}$ when it acts on the edge of the plate. The ultimate bearing capacity is about $51.5 \mathrm{kN}$ at the angle, and the ratio of the bearing capacity at the edge, angle and center of the plate is $98.3 \%$, $86.5 \%$ respectively.

In Fig. 6b, it can be seen that the ultimate bearing capacity of single-layer glass is $21.6 \mathrm{kN}$ when acting in the central position; the ultimate bearing capacity is about 17.0 $\mathrm{kN}$ when acting in the edge of the plate. The ultimate bearing capacity is about $14.1 \mathrm{kN}$ when acting in the corner of the plate, and the ratio of the plate edge, the plate angle and the center of the plate is $78.7 \%$ and $64.8 \%$ respectively. Under the same boundary condition and load position, the maximum change of the ultimate bearing capacity and displacement of single-layer glass and laminated glass is in the middle of the plate and the minimum is in the angle of the plate, and the bearing capacity of laminated glass is more than 3 times of that of single-layer glass plate. The load displacement curve has the same trend and shows linear change in the above position.

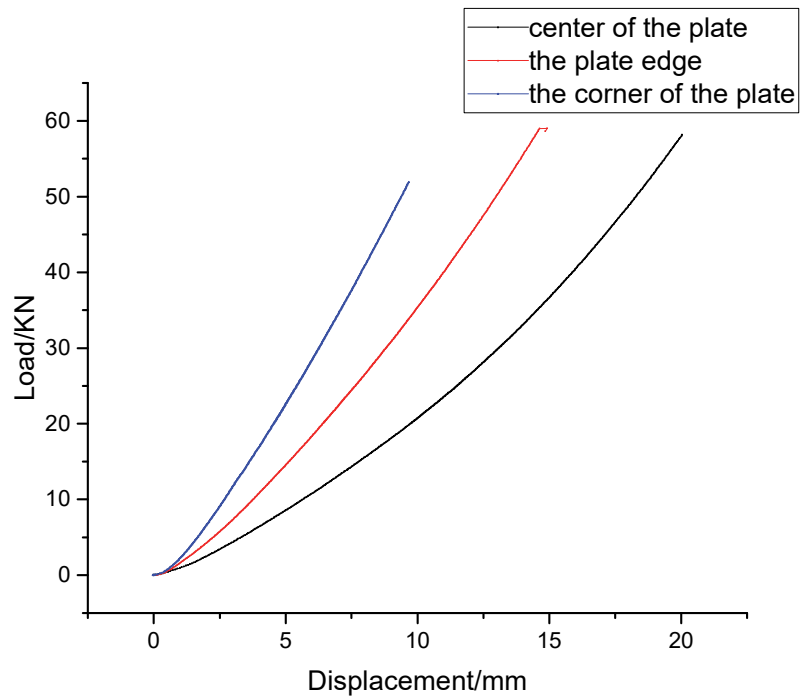

(a) Laminated glass

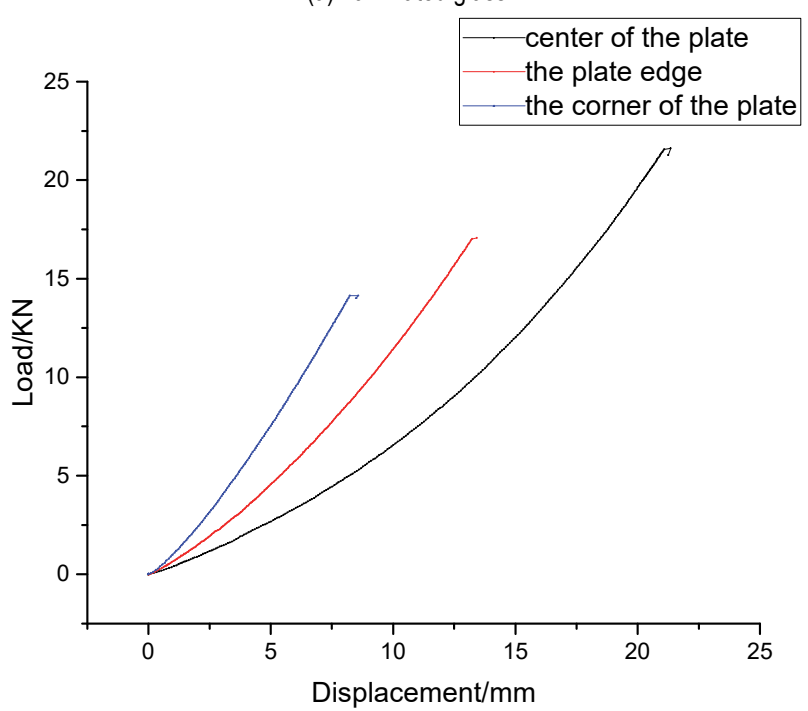

(b) Single layer glass

Figure 6 Load displacement curve of laminated glass under different stress positions

\subsection{LOAD VERIFICATION}

From the point of view of meeting the structural strength requirements, the load acting on the corner of the plate is the most unfavorable working condition, and from the point of view of meeting the structural stiffness requirements, the load acting on the center of the plate is the most unfavorable working condition. Therefore, through the bearing capacity test of laminated glass plate under multiple sets of wheel load, the size of the wheel pressure contact surface in the test is $100 \times 200 \mathrm{~mm}$, the boundary condition of the glass plate is simply supported on four sides. The wheel load of 0.8 times, 1.0 times, 1.2 times, 1.5 times, 1.8 times and 2.0 times is respectively given under the above two working conditions. The maximum strain and maximum deformation of the laminated glass plate are obtained, as shown in Tab. 2 and Tab. 3. The elastic modulus of glass material is taken as it is $8.8 \times 10^{4} \mathrm{MPa}$. According to the design value of glass strength under long-term load specified in technical code for application of building glass JGJ113-2015, the strength of $12 \mathrm{~mm}$ tempered glass in the middle of the plate is 42 $\mathrm{MPa}$, the edge strength is $34 \mathrm{MPa}$, and the end strength is $30 \mathrm{MPa}$. It can be seen that the maximum tensile stress of the glass bridge deck under normal use meets the strength requirements of the specification [13-16].

Table 2 Correspondence between strain, stress and maximum deformation and load when the load acts on the center of the plate

\begin{tabular}{|c|c|c|c|c|}
\hline No. & $\begin{array}{c}\text { Load } \\
\text { multiple }\end{array}$ & $\begin{array}{c}\text { Maximum } \\
\text { tensile strain / } \\
\mu \varepsilon\end{array}$ & $\begin{array}{c}\text { Maximum } \\
\text { tensile stress / } \\
\mathrm{MPa}\end{array}$ & $\begin{array}{c}\text { Maximum } \\
\text { deformation / } \\
\mathrm{mm}\end{array}$ \\
\hline 1 & 0.8 & 197 & 17.3 & 2.75 \\
\hline 2 & 1.0 & 249 & 21.9 & 3.44 \\
\hline 3 & 1.2 & 306 & 26.9 & 4.13 \\
\hline 4 & 1.5 & 369 & 32.5 & 4.82 \\
\hline 5 & 1.8 & 459 & 40.4 & 5.89 \\
\hline 6 & 2.0 & 517 & 45.5 & 6.59 \\
\hline
\end{tabular}

Table 3 Correspondence between strain, stress and maximum deformation and load on the corner of the plate

\begin{tabular}{|c|c|c|c|c|}
\hline No. & $\begin{array}{c}\text { Load } \\
\text { multiple }\end{array}$ & $\begin{array}{c}\text { Maximum } \\
\text { tensile strain / } \\
\mu \varepsilon\end{array}$ & $\begin{array}{c}\text { Maximum } \\
\text { tensile stress / } \\
\text { MPa }\end{array}$ & $\begin{array}{c}\text { Maximum } \\
\text { deformation / } \\
\mathrm{mm}\end{array}$ \\
\hline 1 & 0.8 & 221 & 19.5 & 1.62 \\
\hline 2 & 1.0 & 312 & 27.5 & 1.89 \\
\hline 3 & 1.2 & 416 & 36.6 & 2.30 \\
\hline 4 & 1.5 & 493 & 43.4 & 2.71 \\
\hline 5 & 1.8 & 603 & 53.1 & 3.31 \\
\hline 6 & 2.0 & 658 & 57.9 & 3.57 \\
\hline
\end{tabular}

\section{CONCLUSION}

Before the damage of single-layer glass, the four corners of the glass plate are obviously cocked up, no obvious cracks are found. The damage process is very rapid. The glass cracks instantly and flies around rapidly. The glass fragments at the corners of the plate fly nearly 5 meters away. The distance of the glass fragments in the middle of the plate is relatively small, but the glass fragments are basically kept at obtuse angle, which greatly reduces the injury to people. Before the damage of laminated glass, the state is the same. Like single layer glass, when laminated glass plate is damaged, the bottom glass plate cracks instantly, but there is no glass fragments flying out of the bottom glass, only fine glass slag falls off.

The boundary support condition has a great influence 
on the stress of glass plate. The bearing capacity of laminated glass under the boundary condition of simple support on both sides is about $71.8 \%$ of that under the boundary condition of simple support on four sides; the ultimate bearing capacity of single glass under the boundary condition of simple support on both sides is about $51.4 \%$ of that under the boundary condition of simple support on four sides.

The load position has a significant effect on the stress of the glass plate. The ratio of the bearing capacity of the edge, angle and center of the laminated glass plate is $98.3 \%$ $86.5 \%$ respectively. The ratio of the bearing capacity of the edge, angle and center of the single glass plate is $78.7 \%$, $64.8 \%$ respectively. The load displacement curve trend of the center, edge and angle of the glass plate is the same, showing a linear change.

In this paper, the bearing capacity test of glass bridge deck under wheel load is carried out to study and analyze the bearing capacity performance of glass bridge deck under the condition of boundary, position and number of layers of wheel load, so as to provide a reference for the practical engineering of glass bridge deck.

There are some problems in the design of glass bridge deck, such as the selection of safety factor and the calculation of equivalent thickness of laminated glass panel. If these problems cannot be solved, it will seriously hinder the promotion and application of this structure.

\section{Acknowledgments}

The work was supported by the National Natural Science Foundation of China (51878059); Shaanxi Natural Science Foundation Project (2018JQ5219); Nanyang science and technology research project in Henan Province (2019KJGG030) (2019KJGG031).

\section{REFERENCES}

[1] Asik, M. Z. \& Tezcan, S. (2005). A mathematical model for the behavior of laminated glass beams. Computers \& Structures, 83(21-22), 1742-1753. https://doi.org/10.1016/j.compstruc.2005.02.020

[2] Shao, X. (2015). Review on Studies on Mechanical Properties of SGP. Hans Journal of Civil Engineering, 04(03), 143-150. https://doi.org/10.12677/HJCE.2015.43018

[3] Wang, X., Zhang, Q., Tao, Z., et al. (2012). Theoretical and experimental study on bearing capacity of four-sided simply supported laminated glass. Building Structure, (02), 173-175. https://doi.org/10.19701/j.jzjg.2012.02.035

[4] Wang, Y., Zhang, H., \& Shi, Y. (2005). Analysis of design calculation method for glass load-bearing structure. Building Science, (06), 26-30. https://doi.org/10.3969/j.issn.1002-8528.2005.06.006

[5] Wang Y., Shi Y., \& Zhang H. (2005). Engineering application and design analysis of glass load-bearing structure. Industrial Construction, (02), 6-10. https://doi.org/10.3321/j.issn:1000-8993.2005.02.002

[6] Wang, Y., Zhang, H., \& Shi, Y. (2006).Experimental study on bearing and stability of in-plane curved glass sheets. Journal of Tsinghua University (Natural Science Edition), (06), 773776. https://doi.org/10.3321/j.issn:1000-0054.2006.06.006

[7] Wang, Y., Zhang, H., \& Shi, Y. (2008). Finite element analysis of bearing performance of in-plane curved glass sheets. Building Structure, (02), 120-122.

https://doi.org/10.19701/j.jzjg.2008.02.034
[8] Liu, Q., Huang, X., Han, W., Cui, M., \& Fu, R. (2018). Study on the bending behavior of laminated glass beams. Building Science, (05), 44-49. https://doi.org/10.13614/j.cnki.11-1962/tu.2018.05.007

[9] Yin Y., Zhang Q., \& Huang Q. (2004). Experimental study on bearing properties of point-supported hollow and laminated glass. Journal of Building Structures, (01), 93-98. https://doi.org/10.14006/j.jzjgxb.2004.01.013

[10] Zhang Y., Wang X., \& Yang J. (2018). Experimental study on the impact of rigid body on multi-layer SGP laminated glass. Journal of Inorganic Materials, (10), 1110-1117. https://doi.org/10.15541/jim20170595

[11] Zhang, Z., Zhang, H., Yao, X., \& Hu, H. (2017). Experimental study on failure mode of PVB laminated glass under low velocity impact. Journal of Ordnance Engineering, (38), 113-119.

[12] Tao, Z., Zhang, Q., Chen, J., et al. (2010). Experimental study and finite element analysis of flexural bearing capacity of four-sided part-time laminated glass. Journal of Building Structures, 31(10), 114-119. https://doi.org/10.14006/j.jzjgxb.2010.10.016

[13] Ministry of Construction of the People's Republic of China Glass curtain wall engineering technical specification (JGJ102-2003). Beijing, 2003.

[14] National Standard of the People's Republic of China. Safety glass for building Part 3 Laminated glass (GB 15763.3-2009) China National Standardization Administration Committee, 2009.

[15] People's Republic of China industry standard. Technical regulations for the application of architectural glass (JGJ 113-2015). 2015.

[16] Ministry of Housing and Urban-Rural Development of the People's Republic of China. Technical regulations for the application of architectural glass (JGJ113-2015). Beijing, National Standard of the People's Republic of China, 2015.

\section{Contact information:}

\section{Peng TANG}

(Corresponding author)

School of Highway, Chang'an University,

Xi'an 710064, Shaanxi Province, P. R. China

Nanyang Institute of Technology,

Nanyang 473004, Henan Province, P. R. China

E-mail: tangpeng0830@yeah.net

\section{Sai GONG}

School of Highway, Chang'an University, Xi'an 710064, Shaanxi Province, P. R. China

Nanyang Institute of Technology,

Nanyang 473004, Henan Province, P. R. China

\section{Peng LIANG}

School of Highway, Chang'an University,

Xi'an 710064, Shaanxi Province, P. R. China

\section{Gao CHENG}

School of Highway, Chang'an University,

Xi'an 710064, Shaanxi Province, P. R. China 